\title{
In Memoriam to Professor Andrzej Władysław Wernik
}

With great regret we announce that Professor Andrzej W. Wernik passed away on 24 April 2015 at the age of 76, after a long and serious illness.

Professor Andrzej W. Wernik was the founder and leader of ionospheric research in Poland, one of the pioneers of Polish space research, and world wide renowned specialist in ionospheric physics.

He was the author and co-author of approx. 160 papers published in the peer reviewed journals and conference proceedings on wave propagation in the ionosphere, wave propagation in stochastically inhomogeneous media, ionospheric physics, ionospheric plas-

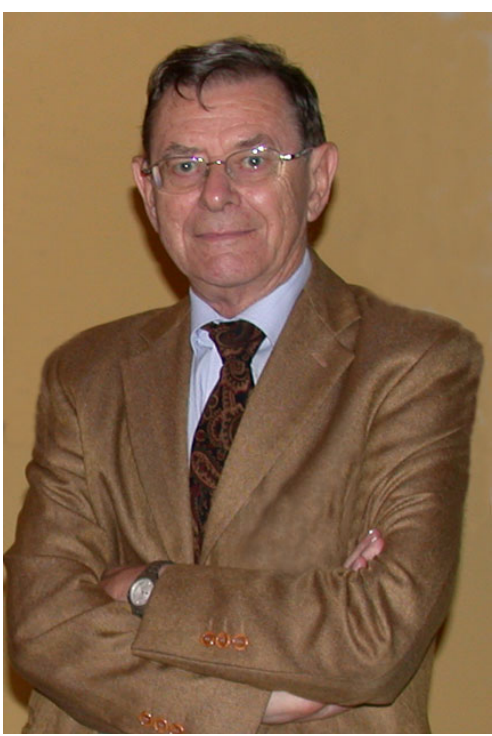
ma turbulence, acoustic-gravity waves in the upper atmosphere, and methods of data analysis.

His M.Sc. degree in astronomy was earned from the Warsaw University in 1960 with M.Sc. thesis "Extinction of the night sky light in an anisotropically scattering atmosphere".

In 1960 he started his scientific career in the Institute of Geophysics of the Polish Academy of Sciences (PAS), to move in 1977 together with his group to the newly established Space Research Center PAS where he has been working until the end of 2014.

In 1963, during his work on geomagnetic data interpretation, he became fascinated with the ionosphere. In 1966 he organized the first regular obser-

Ownership: Institute of Geophysics, Polish Academy of Sciences;

(c) 2015 Stanisławska and Popielawska. This is an open access article distributed under the Creative Commons Attribution-NonCommercial-NoDerivs license,

http://creativecommons.org/licenses/by-nc-nd/3.0/. 
vations of Explorer 22 (Polar Beacon-B) $20 \mathrm{MHz}$ radio signals to study the ionosphere using measurements of Faraday rotation and signal amplitude fluctuations. The same year he initiated the project to construct an advanced receiver for satellite radio beacons at frequencies of 20,30,40,90, and $360 \mathrm{MHz}$, aiming to measure dispersive Doppler frequency at any pair of these frequencies as well as the Faraday rotation. Great accuracy of these measurements made it possible to investigate small frequency scintillations. The apparatus was used since January 1969 to receive beacon signals from Explorer 22, from a number of Intercosmos satellites, and after some modifications, from the geostationary ATS-6 satellite. In such a way for a long time he became engaged in the problem of scintillations in the satellite telecommunication. A number of his works on scintillations were made at that time in cooperation with Dr. Ludwik Liszka of Kiruna Geophysical Observatory in Sweden during several research stays in Kiruna.

His Ph.D. degree in geophysics obtained from the Institute of Geophysics PAS in 1968 was based on the thesis "Effects of non-uniform ionospheric structure on the propagation of radio signals from the Earth's artificial satellites". His Ph.D. supervisor was Prof. Stefan Manczarski, the legendary radio specialist working during the II World War for the Polish underground Home Army.

Later, during his post-doc stay (1972/1973) in the Department of Electrical Engineering of the University of Illinois he worked in cooperation with prof. K.C. Yeh and C.H. Liu on the development of scattering theory of radio scintillations, including multiple scattering and $\mathrm{GHz}$ signals. This work was recognized with the prestigious award of the Scientific Secretary of the Polish Academy of Sciences.

In 1978 Prof. Wernik obtained the D.Sc. habilitation degree from the Institute of Fundamental Technological Research PAS for his scientific works assembled under the title "Theory of scintillations of trans-ionospheric radio waves". The same year he was awarded with the Silver Cross of Merit by the Polish Council of State, the Medal of the Space Research Committee PAS, and the Brown Medal for the Services for State Defense.

In 1968 in Poland the cooperation with INTERCOSMOS organization started. Prof. Wernik used this opportunity to access the Intercosmos satellite ionospheric data (for his research on photoelectrons) and to launch own instruments in space. It materialized only in December 1981 aboard the Vertical-10 rocket with the Polish digital analyzer of plasma density fluctuations probing the mid-latitude ionosphere at altitudes of 200-1500 km. Observations of intense and sharp irregularities of ionospheric plasma density during this experiment allowed to modify the scintillation theory giving better agreement with observations. 
As an acknowledgement of his achievements in science, education, and activity to the benefit of Polish space research the prestigious scientific title of the Professor in Physics has been awarded to him by the President of Poland in 1989.

During his career, Prof. Wernik was involved in a wide international cooperation. Between 1972 and 1988 he visited many times the Department of Electrical and Computer Engineering of the University of Illinois at UrbanaChampaign, USA. In 1984-1987, in cooperation with this University and the University of Oulu he initiated systematic studies of radio scintillations at the Polish Polar Station Hornsund at Svalbard, where HILAT (USAF HIgh LATitude Research Satellite) and Polar Bear (USAF Polar Beacon and Research satellite) radio beacon signals were received.

In 1993 he spent 6 months as a visiting scholar at the National Central University in Chung-Li, Taiwan. With the specialists from the University of Oslo he worked on ionospheric plasma turbulence, with Italian scientists from Istituto dei Sistemi Complessi and Istituto Nazionale di Geofisica e Vulcanologia - on the statistical model of scintillation and space plasma turbulence.

He participated as an expert in many international scientific and educational projects of the European Commission and ESA. Recently it was TRANSMIT project - Training Research and Applications Network to Support the Mitigation of Ionospheric Threats.

Prof. Wernik was a splendid lecturer and promotor of more than $10 \mathrm{Ph} . D$. students. His last student was Dr. Shishir Priyadarshi of India, the grantee of TRANSMIT project. Working under the supervision of Prof. Wernik he defended his Ph.D. thesis "B-splines model of ionospheric scintillation" earning Ph.D. degree in October 2014. This work was based on the last project of Prof. Wernik - scintillation data analysis from GPS receivers placed at the Polish Polar Station Hornsund at Svalbard and in Warsaw.

Prof. Wernik served scientific community in many ways during all his professional life:

a In 1990-1992 he chaired the Commission G Ionospheric Radio and Propagation of URSI.

a In 1996-1999 - Member of the Bureau of the Scientific Committee on Solar-Terrestrial Physics (SCOSTEP).

- In 1996-2000 - Associate Editor of „Radio Science” published by the American Geophysical Union.

- In 1999-2002 - Vice-President of URSI, and

a In 2002-2005 - Vice-President and Treasurer of URSI.

a In 2014-2015 - Honorary Chairman of Commission G of the National URSI Committee. 
- In 2010-2013 - Member of Central Commision for Degrees and Titles.

Prof. Wernik was member of the Research Council of the Institute of Geophysics PAS, Research Council of the Space Research Center PAS, Committee of Geophysics, National URSI Committee, Committee of Polar Research, American Geophysical Union (silver pin), Polish Astronomical Society, Polish Geophysical Society, Advisory Committee of Acta Geophysica published by Springer.

Prof. Wernik was survived by his beloved wife Maria, his daughter Dorota, and his 2 grandchildren Zofia and Jan (Sophie and John). He will be remembered by his friends and coworkers as a nice person of positive attitude to everybody, generous and warm, of noble manners, with science passion, a splendid example of fruitful great scientist and good man. Throughout all difficult moments in the history of Poland before 1989 and the transformation later on that disturbed research work in our Institute, he was always quiet and determined to continue steadily his work, creating so needed peaceful atmosphere around.

Iwona Stanisławska and Barbara Popielawska Space Research Center Polish Academy of Sciences 